\title{
PLATÃO: AS PAIXÕES DA UNIDADE CORPOALMA SEGUNDO O TIMEU
}

\author{
PLATO: THE PASSIONS OF BODY-SOUL UNITY ACCORDING TO THE TIMAEUS
}

Maria Dulce Reis*

\begin{abstract}
RESUMO
Uma das últimas obras escritas por Platão, o Timeu, nos parece um dos textos mais ricos para identificarmos o estatuto das paixões na filosofia de Platão: a origem dessas paixões/afecções, suas propriedades, seu papel no equilíbrio psíquico e na condução das ações humanas. Tal riqueza, profundidade e extensão teórica constituiu grande parte de nossa tese de doutoramento, que visou demonstrar a articulação entre Psicologia, Ética e Política nos diálogos República, Timeu e Leis. No presente texto, nos limitaremos a apresentar nossa interpretação a respeito de passagens da cosmologia do Timeu dedicadas a tratar da constituição da unidade corpoalma humana, o que inclui suas afecções. Nosso recorte limitase a mostrar que as afecções - próprias ao que há de apetitivo, irascível e racional na unidade corpoalma humana - decorrem da encarnação, e o seu direcionamento psíquico é capaz de conduzir os seres humanos à saúde ou à doença, à virtude ou ao vício.
\end{abstract}

PALAVRAS-CHAVE: Platão. Filosofia Antiga. Psicologia. Páthos.

\begin{abstract}
:
One of the last works written by Plato, the Timaeus, seems to us one of the richest texts to identify the status of passions in Plato's philosophy: The origin of the passions/affections, their properties, their role in the psychic balance and the conduct of human actions. Such wealth, depth and theoretical extension constituted a large part of our doctoral thesis, that aimed to demonstrate the articulation between Psychology, Ethics, and Politics in the dialogues Republic, Timaeus, and Laws. In the present text, we shall confine ourselves to our interpretation of passages in the cosmology of the Timaeus devoted to the constitution of the human body-soul unity, which includes its affections. Our clipping is limited to showing that the affections - proper to that which is appetitive, irascible and rational in the human body-soul unity - elapsed from the incarnation and its psychic direction are capable of leading human beings to health or sickness, into virtue or vice.

PALAVRAS-CHAVE: Platão. Filosofia Antiga. Psicologia. Páthos.

\section{INTRODUÇÃO AO ESTATUTO DAS AFECÇÕES/PATHÉMATA DA UNIDADE CORPOALMA NO TIMEU}

Uma das últimas obras escritas por Platão, o Timeu, nos parece um dos textos mais ricos para identificarmos o estatuto das paixões na filosofia de Platão: a origem dessas paixões/afecções ${ }^{1}$, suas propriedades, seu papel no equilíbrio psíquico e na condução das

\footnotetext{
* Doutora em Filosofia Antiga pela UFMG. Professora de Filosofia Antiga da PUC Minas. E-mail: mariadulcereis@pucminas.br.

${ }^{1}$ Pathémata pode ser traduzido por "afecções" ou "paixões"; no singular, páthos. Optamos por "afecções" porque, em português, o termo "paixão" nos parece ter um sentido muito restrito. Já o termo "afecções" permite comportar o enorme leque de afetações e de sentimentos que o composto corpoalma pode sofrer por habitar o sensível. Optamos também por designar esse composto com o termo corpoalma (terminologia não existente em
} 
ações humanas. Tal riqueza, profundidade e extensão teórica constituíram grande parte de nossa tese de doutoramento ${ }^{2}$, que visou demonstrar a articulação entre Psicologia, Ética e Política nos diálogos República, Timeu e Leis. No presente texto, nos limitaremos a apresentar nossa interpretação a respeito de passagens da cosmologia do Timeu dedicadas a tratar da constituição da unidade corpoalma humana, o que inclui suas afecções. Nosso recorte limitase a mostrar que as afecções - próprias ao que há de apetitivo, irascível e racional na unidade corpoalma humana - decorrem da encarnação e o seu direcionamento psíquico é capaz de conduzir os seres humanos à saúde ou à doença, à virtude ou ao vício.

\section{A ORIGEM DAS PAIXÕES: A ENCARNAÇÃO}

O texto do Timeu tem início com um diálogo entre Sócrates e o pitagórico Timeu (17c-19c3), personagem que fará a narrativa de um mito em que situa o lugar do ser humano no universo, dentre outros pontos: "participamos da natureza humana, razão de sobra para aceitarmos, em semelhante assunto, o mito mais verossímil, sem pretendermos ultrapassar seus limites"3 (29d). Essa obra de Platão retrata, nesse sentido, uma cosmologia de sua autoria. Sobre a extrema complexidade do texto do Timeu remetemos o leitor a um estudo nosso que leva em consideração ampla bibliografia ${ }^{4}$. Tomemos como foco a origem das paixões humanas.

Na narrativa mítica do Timeu, o deus artesão, o Demiurgo, atribui aos deuses-filhos a produção demiúrgica da raça humana:

Se eu os fizesse nascer de mim, se eles participassem da vida por mim, eles seriam iguais aos deuses. Portanto, a fim de que, por um lado, eles sejam mortais e, por outro lado, a fim de que o todo seja realmente todo, aplicai-vos, segundo vossa natureza, a fabricar os seres vivos. Imitai a ação de meu poder, quando de vosso próprio nascimento. E, de acordo com $o$ quanto deles convém ser homônimo com os imortais, isto que é dito divino e condutor daqueles que não cessam de praticar a justiça e dos que querem segui-la, tendo semeado e principiado, eu darei a vós. E, de resto, revestindo o mortal com o imortal, produzi seres vivos, dando a eles nutrição, fazei-os crescer e, quando eles perecerem, recebei-os novamente junto de vós (41cd).

português), visando enfatizar esse estado de comunhão que pretendemos mostrar descrito nas passagens que traremos à discussão.

${ }^{2}$ Reis (2010).

${ }^{3}$ Em nossas citações do Timeu, seguiremos a tradução francesa de Brisson (1992), com modificações. Para leitura comparativa, utilizamos a tradução de Rivauld (1956), bem como a de Nunes (1986).

${ }^{4}$ Reis (2010). 
O Demiurgo comunica as "leis do destino" à raça humana (nómoi eimarménoi; 41e23), o que nos leva a identificar a origem das paixões na configuração da unidade corpoalma humana. Quais seriam essas "leis do destino"? São elas:

- nasce, necessariamente, a percepção sensível /aísthesin, oriunda de afecções violentas (42a /1 a lei). Ao "confeccionarem" o composto corpoalma humano, os deuses geram a raça humana submetida a leis necessárias. Comenta Reydams-Schils (1997, p. 264) quanto às afecções sensíveis, que "os pathémata aìsthetiká são o resultado da encarnação humana”, pois as almas humanas serão afetadas pelo sensível, posição que também é a de Lisi (2005, p.67). Veremos que, ao retomar essa narrativa, em 69c-e, Timeu volta a tratar da "construção" da espécie mortal da alma humana "no corpo", como "cheia de afecções terríveis e inevitáveis".

- nasce o desejo lérota, uma mescla de prazer e sofrimento, por outro lado, o medo Iphóbon, a ira Ithymòn e todas as afecções que se seguem a essas e todas aquelas que lhes são contrárias (42a $/ 2^{\mathrm{a}}$ lei). Não nos parece claro que o éros possua o estatuto de afecção nessa passagem, pois Platão o distingue das afecções do medo, da ira e todas as demais, distinção que se encontra também em 69c2-d6. Éros é tratado aqui como uma mescla (memeignénon /mignymi, mesclar) das afecções de prazer e sofrimento. Wilford (1959, p.58) comenta que o éros surge com a encarnação, sendo assim, "encarnação cria desejo; e desejo, razão".

- a transmigração das almas: aquelas almas que dominarem /kratésoien essas afecções viverão na justiça (e retornariam à morada divina) e aquelas que não dominarem viverão na injustiça (e por isso passariam a uma natureza feminina em uma segunda encarnação e, persistindo no mal, passariam a animais em uma encarnação subsequente) (42c-d / $3^{\mathrm{a}}$ lei). A passagem em questão aponta uma possível finalidade no propósito da encarnação da alma: o exercício da virtude da justiça, pelo domínio dessas afecções, conduziria a alma de volta à sua condição originária - livre das encarnações e suas consequências. A paligenesia, ametempsicose e a doutrina da retribuição encontram-se presentes no texto do Timeu, destacadamente em 41e-42d e em $90 \mathrm{e}-92 \mathrm{c}$.

- A necessidade de dominar as paixões: as almas deveriam submeter à "revolução do mesmo" (um dos dois círculos do princípio imortal da alma humana, o que permite a 
relação com o inteligível $)^{5}$ aquilo que se uniu ao seu ser e é feito de fogo, água, terra e ar, sendo tumultuoso e irracional /álogon; e só após tê-lo dominado pela razão /lógoi é que retornariam /aphíkoito à forma de seu estado primeiro e melhor (42c-d /4 lei).

Nesse ponto encontramos a importância do direcionamento das paixões pelo que há de racional na alma humana, de modo a dominar aquilo que é tumultuoso, desprovido de razão, as afecções irracionais surgidas por ocasião da encarnação, já indicadas na passagem anterior. O retorno à condição inicial da alma humana (a condição de uma vida bem-aventurada junto às moradas divinas) só ocorreria através de uma superação dessa “dominação do sensível” sobre a alma humana, isto é, através da recuperação, pelo círculo do mesmo, do domínio da alma como um todo, pelo exercício da razão /lógoi.

- O fluxo e a intensidade das impressões sensíveis atravessando o corpo e chegando à alma (o que é denominado de sensações ${ }^{6}$ ) agitam as revoluções da alma imortal (43cd). Desse modo, as sensações chegam a entravar lepédesan a revolução do mesmo e a deslocar /diéseisan a revolução do outro ${ }^{7}$ (43d), isto é, os círculos do princípio imortal da alma humana, que estarão mergulhados no erro/pseudê̂s e na ausência de inteligência /anóetoi (44a) pela ação da encarnação. É pelo efeito de todas essas afecções que, a cada vez ${ }^{8}$ que a alma encarna, ela será, a princípio, desprovida do ver inteligível /ánous (44a-b); contudo, quando diminui o fluxo daquilo que faz crescer e nutrir o corpo, as revoluções da alma voltam à via que é a sua, recuperando a sua calma. Quando as revoluções de cada um dos círculos que seguem sua trajetória natural são redirecionadas (corrigidas), elas atribuem corretamente os predicados de outro e de mesmo, tornando sensato lémphrona aquele que as possui (44b).

- A correta nutrição para o composto almacorpo para uma condição de equilíbrio e justiça: com a nutrição de uma educação correta /orthé trophè paideúseos, tal homem torna-se completamente são /hygiés e inteiro /holókleros, após ter escapado à mais

\footnotetext{
${ }^{5}$ A respeito da composição da alma cósmica no Timeu, bem como dos círculos do mesmo e do outro componentes do princípio imortal da alma humana, ver Reis (2010, parte 1, capítulo 1).

${ }^{6}$ Retomada de 42a. Como observa Cornford (1948, p.148, n. 3), "na visão de Platão ambas - sensações e qualidades - são movimentos".

${ }^{7}$ Para Brisson (1992, p. 242, n. 271), essa passagem leva em consideração que "a parte racional da alma humana é, em uma escala reduzida, a réplica da alma do mundo".

${ }^{8}$ A conjunção ótan pode ser compreendida como "quando", mas também como "cada vez que". Esta última é a interpretação de Brisson (1992, p.139) e, a primeira, a de Rivaud (1956, p.160). Optamos por "cada vez que", que permite a possibilidade de diversas encarnações, o que parece mais coerente com a totalidade do texto do Timeu.
} 
grave doença ${ }^{9}$; mas, ao contrário, se ele se mostra negligente /katamelésas e percorreu a vida faltoso /kholèn, é inacabado /atelès ${ }^{10}$ e privado de inteligência /anoetós, ele retorna ao Hades (44c).

Na cosmologia do Timeu, a configuração da unidade corpoalma humanos (dotada do que há de apetitivo, irascível, racional) é compreendida como uma das ações inteligentes por parte dos deuses. A tripartição da alma humana pressupõe, no mínimo, uma primeira encarnação, pois o princípio mortal da alma humana, sobretudo o que ela possuirá de irascível e de apetitivo, surge pela realidade da encarnação, quando a alma, necessariamente, passará a ter que lidar (sofrer ação e agir) com o sensível. A alma humana encarnada está sujeita ao engano, à opinião falsa, à injustiça na alma (a sublevação de uma parte da alma, que não é destinada a governar, no sentido de dominar a alma como um todo) e à ação injusta. Pode-se deduzir, de tais "leis do destino das almas", que a alma humana é responsável por seus males, sofrimentos e ações (42d-e) ${ }^{11}$. Encontra-se aberto ao ser humano a construção de sua vida interna, de suas relações com os demais, com a vida política e com o cosmo.

\section{O CARÁTER INEVITÁVEL DAS AFECÇÕES DO COMPOSTO CORPOALMA E SEU DIRECIONAMENTO}

Após fazer uma "nova descrição do universo" (52d3), conforme os três princípios que antecedem a geração do céu (o ser, o receptáculo, a geração), a narrativa mítica do Timeu volta a mencionar o composto almacorpo humano e suas afecções ou paixões (69c-73c). Vejamos:

E, dos viventes divinos, ele mesmo [o Demiurgo] foi o artesão; quanto à geração dos viventes mortais, ele a confiou àqueles demiurgos gerados por ele. Esses, imitandoo, após terem recebido o princípio imortal da alma (arkhèn psykhês athánaton), envolveram-no em um corpo mortal e deram a ele, por veículo, o corpo todo inteiro; além disso, eles construíram nesse corpo um outro gênero de alma, que é mortal (tò thnetón) e que comporta, nele mesmo, afecções terríveis e inevitáveis: a princípio, o prazer, a maior isca que provoca o mal, em seguida asdores, fuga dos

\footnotetext{
${ }^{9}$ Como aponta Brisson (1992, p. 243, n. 281), Platão estaria fazendo referência à ignorância (44a, 86b e 88b). Pensamos que pode tratar-se da injustiça na alma, o que não exclui a ignorância.

10 "Inacabado", seguindo a tradução de Rivaud (p.161). Brisson (1992, p.179) traduz atelès por "sem ter sido iniciado", argumentando que Platão faz uso do vocabulário dos Mistérios em vários Diálogos.

${ }^{11}$ Para Cornford (1948, p.144) essa é a principal lição presente nas leis do destino das almas. No caso do Timeu, a "lei" finaliza indicando que "après leur avoir fait connaître tous ces décrets pour ne pas être responsable du mal que par la suite pourrait commettre l'une ou l'autre, il sema ces âmes les unes sur la terre, les autres sur la lune, et celles qui restaient sur tous les autres instruments du temps" (42d-e). Brisson (1992, p.135, n.250) considera que tal é a mensagem também da conclusão do Timeu, em 90b-d.
} 
bens, e ainda a temeridade ${ }^{12}$ e o medo, um par de conselheiros sem discernimento, o arrebatamento, rebelde aos conselhos, e a esperança, fácil de decepcionar. Tendo feito uma mistura com essas afecções, a sensação irracional e o desejo, de onde vem tudo o que é empreendido, eles compõem a espécie mortal submetida à necessidade (69c2-d6, grifo nosso).

A passagem menciona a existência de um princípio imortal da alma humana (não submetido à geração e à corrupção) e de um gênero mortal da alma humana construído "no" corpo, o que interpretamos como a construção do que há de apetitivo, irascível e racional (mortais) no ser humano, dada a caracterização das afecções que lhe são próprias. Outro diferencial da espécie mortal da alma humana em relação ao princípio imortal é que aquela se compõe de pathémata, aisthései alógoi e éroti. O éros é mencionado de modo separado em relação às afecções, o que nos faz levantar a hipótese de que ele não é uma paixão da alma e sim uma das condições da alma encarnada, assim como o são as afecções próprias aos três gêneros da alma. A respeito do éros, das sensações e das afecções não é dito que sejam elementos bons ou maus para o ser humano, apenas que são características próprias à unidade corpoalma humana submetida ao campo da causalidade necessária.

A passagem em questão (69c2-d6) caracteriza as afecções próprias ao que há de apetitivo, irascível e racional do composto corpoalma e também sugere uma fonte potencial para o mal moral: os prazeres. O prazer e o sofrimento são afecções do apetitivo ("a princípio, o prazer, a maior isca que provoca o mal, em seguida, as dores, fuga dos bens"). O medo, a temeridade, o arrebatamento são afecções do irascível ("e ainda a temeridade e o medo, um par de conselheiros sem discernimento, o arrebatamento, rebelde aos conselhos”). Quanto à "esperança”, visto que o sentido parece ser o de "um engano" (“a esperança, fácil de decepcionar"), levantamos aqui a hipótese de que se trate de uma afecção do gênero racional.

A confecção da raça humana mortal inclui, além dessas afecções, a impressão sensível irracional /aisthései alógoi e o desejo léroti; assim como em 42a, o desejo léros surge devido à encarnação da alma e distingue-se do conjunto das afecções. Discordamos de Kelsen (1998, p. 396) quando ele afirma, referindo-se à espécie mortal da alma humana e seus pathémata, que "o significado dessa segunda alma é claro: ela é a sede do mal, ou seja, de todas as emoções anímicas de seus representantes". ${ }^{13}$ Contrariamente a essa, temos a posição de Johansen (2000, p.107), com a qual concordamos, de que "os deuses menores organizam

\footnotetext{
${ }^{12}$ Thárros: temeridade, impulsividade.

${ }^{13}$ Discordamos também da associação feita por Kelsen (1998, p. 397) entre o mal e o corpo.
} 
essas afecções para servirem racionalmente, dentro do ser vivente inteiro". As afecções são condição inevitável do composto corpoalma humano.

Mais adiante na narrativa, observa-se a confecção, pelos deuses-filhos, da composição corpoalma (o que justifica nossa designação corpoalma) pois os gêneros apetitivo, irascível e racional são estabelecidos em regiões que lhe são apropriadas:

\begin{abstract}
O que da alma participa da coragem e do ânimo, que é amigo da vitória, eles estabeleceram mais próximo da cabeça, entre o diafragma ${ }^{14}$ e o pescoço para que ouvisse a razão (lógou) e pudesse estar em comunicação com ela a fim de conter, pela força, a espécie dos apetites, todas as vezes que esses últimos não desejassem, de modo algum, ser persuadidos consentidamente pela razão, a partir de sua acrópole. [...] Por outro lado, tudo o que, na alma, tem apetite de comida e bebida e que se sustenta como necessidade através da natureza do corpo, eles estabeleceram na região do corpo que está entre o diafragma e o limite do umbigo. Em toda essa região, eles fabricaram uma espécie de nutridor para a alimentação do corpo; e o prenderam ali como uma cria selvagem que é necessário nutrir bem, se um dia devesse existir uma raça de mortais (thnetòn génos), a fim de que, portanto, sempre ocupando-se no nutridor e morando o mais distante daquele que delibera, fizesse o menos possível de tumulto e barulho, permitindo que aquele que é mais poderoso delibere em paz sobre o que é comum ao todo e o que é particular; por isso the atribuíram este lugar, nesta ordem. (70a2-7; 70d7-71a3).
\end{abstract}

A passagem faz referência às propriedades do apetitivo, do irascível e do racional. Um gênero é aquele que participa da coragem e do ânimo, o que é amigo da vitória, sendo capaz de aliar-se à razão no sentido de conter, pela força, os apetites que se opõem a ela: o irascível; outro gênero é aquele que persuade e raciocina a partir de sua acrópole: o racional; e outro gênero distinto a estes é aquele que tem apetite de nutrição e de outras satisfações corpóreas, o que possui apetites que devem ser contidos pela força, o que se assemelha a uma cria selvagem $^{15}$, aquele que deve ser nutrido para que exista a raça humana mortal e que deve situar-se o mais longe possível daquele que delibera, para não perturbá-lo em suas deliberações, provocando conflitos: o apetitivo. A passagem traz termos metafóricos como o “ouvir a razão" por parte do irascível. Trata-se, esta, de uma "metáfora epistêmica”, nos termos de Pender (1997, p. 286), pois dotada de valor cognitivo irredutível a uma linguagem literal, também podendo ser chamada de metáfora "antropomórfica", pois os diferentes gêneros da alma são tratados como indivíduos que agem como tal.

\footnotetext{
${ }^{14}$ Apesar de o termo grego ser tônphrenôn e não diaphragma (que possui uma única ocorrência em 70a2), seguimos a opção de traduzir aquele também por diafragma, como também o fazem alguns tradutores, como Rivaud (1956) e Nunes (1986).

${ }^{15}$ Característica também citada no livro IX da República 588d-e, quando Sócrates fala dos apetites selvagens e dos não cultivados, entre outros, comparando o apetitivo a um monstro de muitas cabeças.
} 
Outras passagens mostram a unidade do composto corpoalma humano - o que nos oferece material para nos contrapormos à corrente interpretação de que haveria um dualismo corpo e alma em Platão - bem como revelam o caráter inevitável de suas afecções, como aquelas que narram a função de órgãos como o coração, o pulmão, os intestinos, a medula, o que é dotado de finalidade benéfica, "para que o melhor /tòbéltiston possa ter hegemonia /hegemoneîn sobre o todo" (70b9-c1).

O coração estaria capacitado a fazer a guarda das ordens da razão, pois, diante da ameaça de algum perigo externo ou interno, "quando a razão /logou alerta que algo injusto ládikos ocorre nos membros, seja por ações externas ou por apetites lepithymiôn internos" (70b), o coração tem o furor da cólera despertado e "através de todos os estreitos vasos" sanguíneos (isto é, pelo sistema circulatório), ele transmite ao corpo as ordens e ameaças da razão, visando a conter o fator desencadeante do desequilíbrio. O pulmão (70a-b) apaziguaria e refrescaria os batimentos do coração quando este se alterasse. Por esse motivo, o pulmão foi feito esponjoso, mole e desprovido de sangue. Por suas cavidades, ele recebe o ar, além de líquidos, refrescando e amortecendo o coração que, fatigando menos, seria capaz de auxiliar a razão /lógoi, com o ânimo /metà thymoû (70d). O pulmão auxilia, portanto, o acordo entre o irascível e o racional e o governo deste último.

Já o fígado (71b1-5) é associado ao gênero apetitivo da alma, fabricado por um deus na mesma região de "nutrição" do corpo (70e2-3), isto é, entre o diafragma e o limite do umbigo, a região do apetitivo. Relaciona-se ao sistema humoral, sendo capaz de produzir humores como o chamado fleuma, bem como a bile (a doce e a amarga ou "negra"), que estarão diretamente ligados à produção dos sentimentos de medo, alegria ou tristeza, alegria /híleón, serenidade leuémeron, bem como à adivinhação /manteíai. Interpretamos que o par fígado-intestinos se associa ao gênero apetitivo da alma. Os intestinos foram "enrolados várias vezes sobre si mesmos para que os alimentos não o atravessassem muito depressa" (72e), o que leva o organismo a evitar a gula e também o risco de que doenças dela decorrentes conduzam a raça mortal ao desaparecimento antes de sua completude /teleutôi (73a). Os deuses, já prevendo essa intemperança, teriam buscado evitá-la colocando certos limites aos órgãos digestivos, ou seja, impondo limites já aos próprios órgãos do corpo para que o apetitivo não conduza “o todo corpo-alma mortal” à destruição. Um outro risco dessa intemperança no comer e no beber é que ela tornaria a raça humana "estrangeira às musas e à filosofia, surda àquilo que há em nós de mais divino" (73a). 
Quanto à medula /tòn myelòn (encéfalo, medula espinhal e medula óssea ${ }^{16}$ ), o deus implanta e fixa as espécies de alma Itôn psykhôn géne (73c3-4), mortal e imortal, estabelecendo os laços "da alma toda inteira" (73d5-6). Como a alma, sendo incorpórea, pode ser dita "implantada" e "fixada" no corpo? Trata-se, como observa Pender (1997, p. 283-284), de uma linguagem metafórica - uma metáfora "ilustrativa", nos termos da autora - mostrando que a alma difere do corpo, mas está unida a ele nas raças mortais. A ligação entre incorpóreo (alma) e corpóreo (sensível) é possível, tanto no kósmos como, particularmente, no homem, porque a resistência oferecida pela necessidade não é total (69d). O círculo do outro, presente na psykhé cósmica e na psykhé humana, possibilita à alma uma ligação (cognitiva, cinética, ética) com o sensível. Tanto Pender (1997, p. 285) como Brisson (1998, p. 48-50) observam que Platão usa vocabulário agrícola ao tratar da fabricação da medula e sua união com a alma; semear, enxertar, enraizar, nutrir, frutificar, irrigar. Essa linguagem metafórica mostra a íntima relação entre a alma e os diversos elementos e órgãos do corpo. A medula terá certa relação com os movimentos próprios da espécie imortal da alma e da espécie mortal. Pois, à porção da medula que deveria receber a semente divina /tò theîon spérma (73c7) ele deu a forma esférica, construindo o encéfalo ${ }^{17}$, que será abrigado pela cabeça. Devemos aqui recordar que os dois círculos do "princípio imortal” possuem movimento circular. Embora o texto não o afirme explicitamente, o formato esférico do encéfalo parece visar à viabilização de tal movimento ${ }^{18}$.

A outra porção da medula (a espinhal) é destinada a conter o que é restante e mortal da alma /tò loipòn kaì thnetòn tês psykhês émelle (73d2-3) e ele a dividiu em figuras /skhémata redondas e alongadas. Portanto, para acolher a espécie mortal (aquela que diz respeito ao apetitivo e ao irascível), é fabricada uma morada sensível envolvendo um formato que comporte os movimentos circular e retilíneo. O deus envolve a medula com um revestimento ósseo e, ao seu redor, forma o conjunto do corpo. É desse modo que a alma estará ligada Isyndouménes ao corpo, em uma unidade corpoalma, enraizando a raça mortal Itò thnetòn

\footnotetext{
${ }^{16}$ Quanto à medula óssea, é interessante observar que Timeu narra em 74e-75a que haveria porções maiores ou menores de alma revestidas de maior ou menor quantidade de carne, conforme a região da medula óssea participe mais ou menos do nôus e que os ossos que não participam do nôus teriam sido totalmente revestidos de carne. Portanto, a carne parece ser um obstáculo à ação do nôus, presente no "princípio imortal".

${ }^{17}$ Frias (2005, p. 119) observa corretamente que Brisson, à página 249 de seu comentário sobre o Timeu, situa equivocadamente a espécie imortal na medula cervical e não no encéfalo.

${ }^{18}$ Frias (2005, p. 118) ressalta que a "essência divisível" da alma imortal torna possível a ligação da alma com o corpo. Destacamos, de nossa parte, que, sendo a alma intermediária entre os modos de ser divisível e indivisível, isso torna também possível sua ligação com o inteligível.
} 
génos (73b4-5), isto é, tornando efetiva a mímesis da Forma inteligível do vivente total ${ }^{19}$. Todos os órgãos e elementos do corpo são fabricados para garantirem a sobrevivência da raça mortal e para servirem à soberania do gênero racional (o princípio imortal encarnado) sobre os demais. Distúrbios psicofisiológicos podem decorrer não apenas de fatores externos, mas de um desequilíbrio interno da alma. ${ }^{20}$

A partir de 86a, após um extenso trecho narrando a fabricação de cada um dos órgãos, sistemas e elementos da estrutura corporal humana e sua relação com as doenças do corpo, Timeu passa a tratar das "doenças da alma" (86b-87b; 87c-88b) em passagens sobre as quais não nos deteremos aqui, dadas as limitações do presente texto. Mas podemos destacar que Platão atribui como causas inconsentidas ${ }^{21}$ das doenças da alma uma má disposição do corpo e má educação da alma (86d7-e3), assim como a ação de maus discursos e regimes políticos (87a7-b4). Excessos de prazer ou de sofrimentos podem produzir afecções como tristeza, audácia, covardia, esquecimento (86b-87a). A noção de causalidade aparece de modo mais evidente em 87c2 laitíais e, indiretamente, em 87b5, quando Timeu afirma também que "é preciso sempre acusar mais aos geradores (pais) que aos gerados (crianças), aos educadores que aos educandos" (parênteses nossos), ressaltando o papel da educação para a conquista do equilíbrio interno e da possibilidade da ação virtuosa.

\section{CONSIDERAÇÕES FINAIS}

A teoria da alma humana triádica ${ }^{22}$, postulada no livro IV da República, é retomada no Timeu, em passagens como as que apresentamos no presente texto. Na República, após ter demonstrado a existência de três gêneros distintos dalna alma, no livro IV, as afecções próprias a cada gênero são mencionadas (sobretudo nos livros VIII e IX), quando da caracterização das almas dos governantes (tirano, oligarca, timocrata, democrata, rei-filósofo). O prazer e o sofrimento constituem afecções próprias ao gênero apetitivo. A ira e outras afecções (como o medo e a temeridade) são paixões próprias ao gênero irascível. A esperança

\footnotetext{
${ }^{19} \mathrm{O}$ vivente total /tôi panteleî dzóoi (Timeu 30d-31b); o vivente completo e inteligível /tôi teléoi kaì noetôi dzóoi $(39 \mathrm{e})$.

${ }^{20}$ Sobre esse ponto, ver nosso estudo (REIS, 2010, parte 1, capítulo 2); e Johansen (2000, p.105) enfatiza que "as partes mais baixas da alma são geradas para cooperar com a razão", mesmo o apetite de nutrição liga-se a um fim racional, enfoque que não é o mesmo que aquele da República IV. Sobre a cooperação entre corpo e alma, ver todo o texto de Steel (2001).

${ }^{21}$ A noção de causalidade aparece de modo mais evidente em $87 \mathrm{c} 2$ /aitíais e, indiretamente, em $87 \mathrm{~b} 5$, quando Timeu afirma também que "é preciso sempre acusar mais aos geradores [pais] que aos gerados [crianças], aos educadores que aos educandos".

${ }^{22}$ Ver Reis (2009).
} 
nos parece ser vista como uma afecção ligada ao gênero racional, pela expectativa (vã, quando se associa a uma opinião enganosa) de uma realização futura. Tais afecções não são ditas boas nem más. Pois são estados da unidade corpoalma que é capaz de agir e sofrer ações, ser afetada (daí a alma ser referida como "potência" em República 437a-b) tanto externamente (agindo e sofrendo ações em sua relação com o mundo externo) como internamente (os três gêneros da alma agindo e sofrendo ações sobre si mesmos, na interação entre os três, o que resulta na posse de estados de alma que vão da virtude ao vício).

A narrativa mítica do Timeu, ao abordar a geração do composto corpoalma em um estado de unidade, mostra-se coerente com o que já fora afirmado sobre as paixões na República IV-IX, acrescentando para nós, leitores, os eventos da encarnação do princípio imortal da alma humana e da "confecção" dos três gêneros da alma humana "no" corpo como a origem e a causa necessária das afecções próprias a cada um dos três gêneros. Tal narrativa também confirma a defesa, feita por Platão, de que as afecções podem ser conhecidas pelo elemento racional e devem ser equilibradas pela boa formação e educação corpoalma, direcionadas para finalidades benéficas. $\mathrm{O}$ papel preponderante da reta educação voltada para aquilo que é próprio à natureza de cada um dos gêneros na alma continua decisivo como condição para que o ser humano conquiste sua excelência, um estado de alma virtuoso, capaz de agir bem no plano da vida ético-política. Vários pontos da relação entre Psicologia, Ética e Política em Platão serão retomados por Aristóteles, contudo não cabe iniciarmos esse debate no presente texto.

\section{REFERÊNCIAS}

ARISTÓTELES. Ética a Nicômaco. Tradução de Leonel Vallandro e Gerd Bornheim. São Paulo: Edições Victor Civita, 1984. (Os Pensadores).

BAILLY, Anatole. Le Grand Dictionnaire Grec Français. 4. ed. Paris: Hachette, 2000.

BRISSON, L. Le Même et l'Autre dans la structure ontologique du Timée de Platon. Paris: Klincksieck, 1974. Augustin: Academia Verlag, 1998.

CARONE, Gabriela R. Sobre el significado y el status ontologico del demiurgo del Timeo. Méthexis, Buenos Aires, p. 33-49, 1990.

CORNFORD, F. M., Plato's Cosmology. 2. ed. London: Routledge and Kegan Raul, 1948.

FRIAS, Ivan. A relação corpo-alma no Timeu em função do binômio saúde-doença.

Cadernos de Atas da ANPOF, Rio de Janeiro, n.1, 2001, p.111-116, 2001. 
FRIAS, Ivan. Doença do corpo, doença da alma: medicina e filosofia na Grécia Clássica. São Paulo: Loyola, 2005.

JOHANSEN, Thomas. Body, Soul, and Tripartition in Plato's Timaeus. Oxford Studies in Ancient Philosophy, n.19, 2000, p. 87-111.

KELSEN, Hans. A ilusão da justiça. Tradução Sérgio Tellaroli. São Paulo: Martins Fontes, 1998.

LISI, Francisco. A alma do mundo e a alma humana no Timeu. Apontamentos para uma reinterpretação da psicologia platônica. Tradução André Yasbek. Hypnos, São Paulo, 10, 14: p. 57-69, 2005.

OSTENFELD, Erik Nis. Self-motion, tripartition and embodiment. Understanding the Phaedrus - Symposium Platonicum II (congrès). Ed. Livio Rossetti, I, Sankt Augustin: Verlag, 1993, p. 324-328.

PENDER, Elizabeth. The language of soul in Plato's Timaeus. Interpreting the TimaeusCritias. Proceedings of the IV Symposium Platonicum (congrès). Sankt Augustin, Verlag, 1997, p. 281-288.

PLATÃO. República. Tradução M. H. da Rocha Pereira. 7. ed. Lisboa: Fundação Calouste Goubenkian, 1993.

PLATÃO. Timeu. Tradução C. A. Nunes. Belém: Ed. Universidade Federal do Pará, 1986.

PLATÃO.Timée / Critias. Trad. et Com. Luc Brisson. Paris: GF-Flammarion, 1992.

PLATÃO. Timée. Trad. et Com. Albert Rivauld. Tome X. C.U.F. Paris: Les Belles Lettres, 1956.

PLATÃO. Timaios Platonis Opera - T. IV tetralogiam VIII continens [insunt Politia, Timaeo et Critia], recognovit brevique adnotatione critica instruxit Ioannes Burnet. Oxford: Oxford Clarendon Press, 1902.

REYDAMS-SCHILS, G. Plato's World Soul: grasping sensibles without sense-perception. Interpreting the Timaeus-Critias. Proceedings of the IV Symposium Platonicum (congrès), Sankt Augustin: Verlag, 1997, p. 261-266.

REIS, M. D. Psicologia, ética e política: a tripartição da psykhé na República de Platão. São Paulo: Edições Loyola, 2009. (Coleção FAJE).

REIS, M. D. Virtude e vício. Tripartição e unidade da psykhé no Timeu e nas Leis de Platão. Rio de Janeiro: Editora 7Letras, 2010.

STEEL, C. The Moral Purpose of the Human Body. A Reading of Timaeus 69-72. Phronesis, Koninklijke Brill N.V., Leiden, XLVI, n. 2, 2001, p.105-128.

WILFORD, F. A. The status of reason in Plato's psychology. Phronesis, Assen, n. 4, 1959, p. 54-58. 